\title{
TEACHER MOTIVATION AT LAPID SCHOOL AND ITS RELATIONSHIP TO THE ACHIEVEMENT LEVEL OF STUDENTS: CASE STUDY

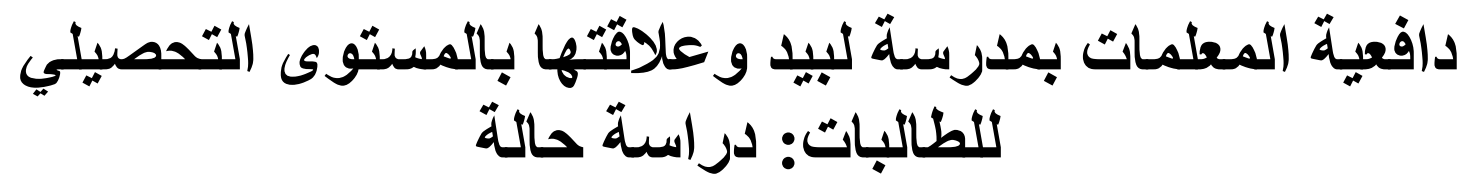

\section{إسحاق بن سليمان بن ناصر العامري \\ Ishaq Sulaiman Nasser Al-Amri ${ }^{1}$, Siti Rafiah Binti Abdul Hamid ${ }^{2}$ and Kamal JI Badrasawi $^{3}$}

${ }^{1}$ Ph.D. Candidate at the Faculty of Education, International Islamic University Malaysia (IIUM): a.alaamri11@moe.om

${ }^{2}$ Assoc. Prof. Dr. at the Kulliyyah of Education, International Islamic University Malaysia (IIUM); srafiah60@iium.edu.my

${ }^{3}$ Asst. Prof. Dr. at the Kulliyyah of Education, International Islamic University Malaysia (IIUM); kamalbadrasawi@iium.edu.my

${ }^{*}$ Corresponding Author

\begin{abstract}
This study discussed the state of motivation at (Lapid) School, and its relationship to the achievement of female students. The problem shows that there is a disparity in the motivation of achievement among the teachers, and this feeling is reinforced by the frequent observations of the complaints and complaints of a large number of teachers from the teaching profession, and some regretted joining this profession. The study aimed to: diagnose the level of female motivation and compare it to the achievement level of female students. Discussing the school factors affecting teacher motivation professionally. And discuss the relationship of the experience factor to the teacher's motivation. Knowledge of parameter proposals to improve professional motivation. The descriptive analytical method was used, and the quantitative and qualitative approach was used in data collection. The research community consisted of Lapid school teachers (73), the research sample reached (21) female teachers. Study tools: the questionnaire and the interview. Resolution: The scale consists of (32) words that measure five basic dimensions. Two questions were prepared for the interview. The results showed that there were (11) teachers with a very high level of motivation, the success rate of their students ranged between $(72.2 \%$ to $100 \%$. (7) Teachers with a high level of motivation, their success rate was between (58.6\% to $100 \%$ ). Less than $90 \%$ have (3) medium motivated female teachers.
\end{abstract}

Keywords: motivation, experience, student achievement.

\section{الملخص}

ناقشت هذه الدر اسة حالة الدافعية بمدرسة لبيد، و علاقتها بتحصبل الطالبات. تظهر المشكلة بوجود

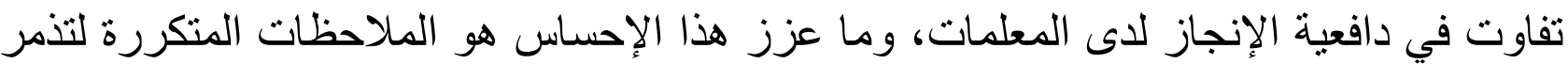
وشكوى عدد كبير من المعلمات من مهنة التدريس، وندم البعض من التحاقه بهذه المهنة. هدفت هذر الإن 
الدر اسة: تشخيص مستوى دافعية المعلمات ومقارنة ذلك بالمستوى التحصيلي للطالبات. مناقشة العو امل المدرسية المؤثرة في دافعية المعلم مهنيا. ومناقنة علاقة عامل الخبرة على دعلى دافعية المعلم. معرفة مقترحات المعلمات لتحسين الدافعية المهنية. استخدم المنهج الوصفي التحليلي، واعتمد المنهج الكمي والنوعي في جمع البيانات. تكون مجتمع البحث من معلمات مدرسة لبيد (73)

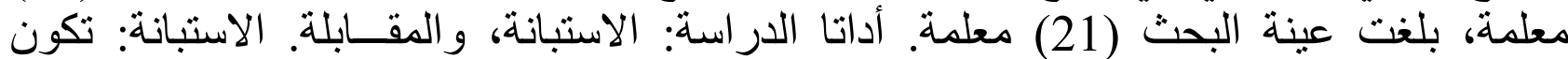
المقياس من (32) عبارة تقيس خمسة أبعاد أساسية. تم إعداد سؤالين للمقابلة. بينت النتائج وجود (11) معلمة بمستوى الدافعية العالية جدا، تراوحت نسبة النجاح طالباتهم بين (72.2\%

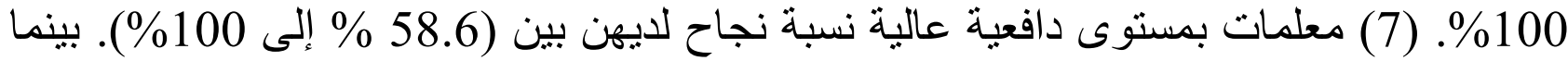
كانت نسب نجاح الطلاب مرتفعة لم تقل عن 90 \% لدى (3) معلمات ذوات الدافعية المتوسطة. كلمات مفتاحية: الدافعية، الخبرة، تحصيل الطالبات.

\section{المقدمــة :}

المعلم والمتعلم هما محور العملية التربوية وعليهما تقوم ، ومن هنا كان الاهتمام بهما حتى تتجح هذه العملية ، وتصل إلى تحقيق الأهداف التربوية المنشودة ، وبناء جيل قوي مسلح بالعلم و القيم و الأخلاق الفاضلة التي تؤهله ؛ لذلك كان لز اما البحث عن الته الوسائل التي ترتقي بالعملية التعليمية بمحوريها المعلم والمتعلم ، ويتعلق موضوع الدافعية حقيقة بالطالب و المعلم ، و إذا كنا بصدي هئه

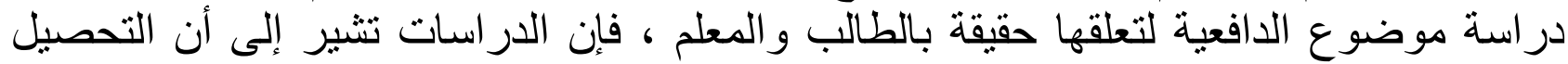

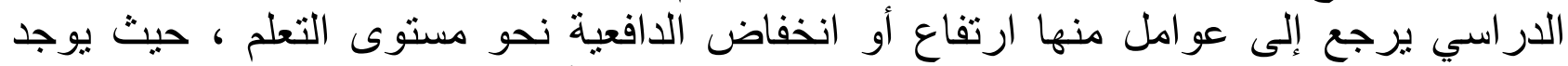

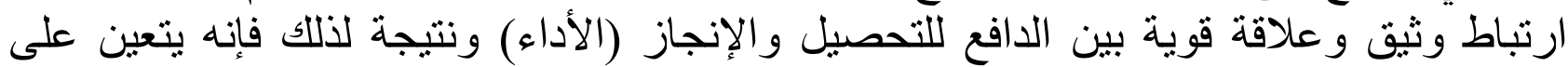
الآباء و المربين تشجيع الأبناء على الإنجاز في شتى المئى المو اقف و الاعتماد على الذات مع ملاحظة أنه كلما ارتفع مستوى الطموح عند المعلم اتجاه تحقيق أهدافه التربوية كلما انتقل ذلك إلى طلى طلابه ، ولما كان للمعلم أكبر الأثر في إيجاد الدافعية وتحريكها لدى طلابه ، كان لز اما أن بتحلى بها المعلم في عمله.

تعني دافعية المعلم مدى ممارسة المعلم لأعماله بدافع الحب للمهنة سواء أكان هذا الدافع نابع من

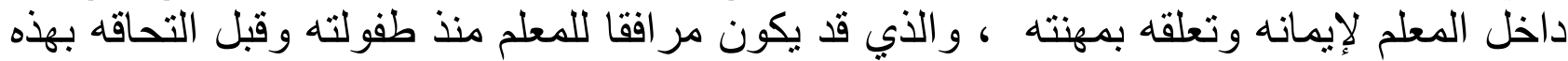

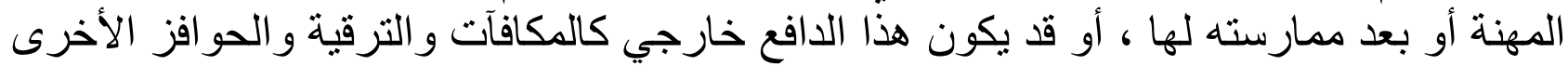
، و تعامل الإدارة و المسئولين.

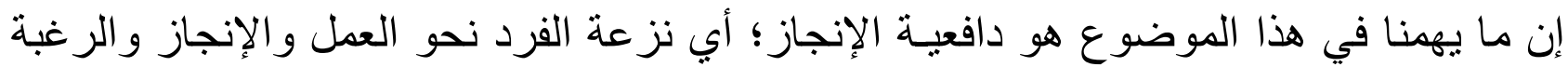

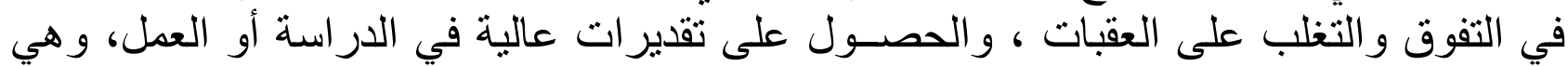

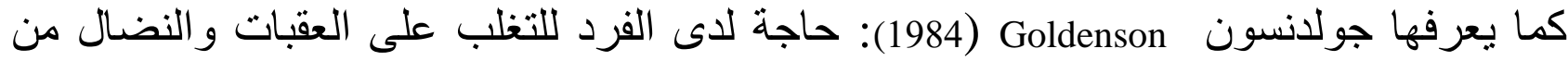

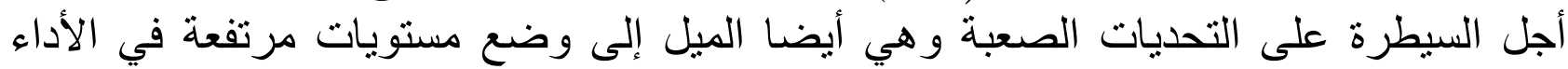
و السعي نحو تحقيقها ، و العمل بمو اظبة شديدة ، ومباشرة مستمرة (الأزرق ، فموضوع الدافعية من المواضيع التربوية المهمة لما لها من دور في تحديد المستوى التحصيلي

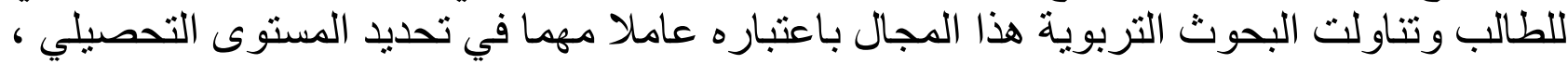

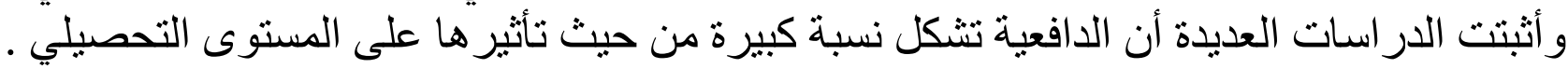




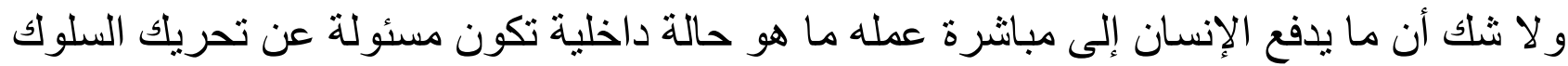

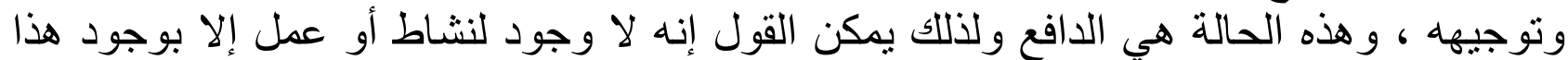

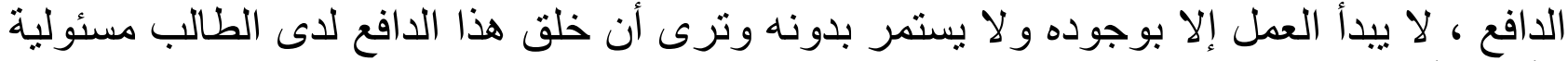

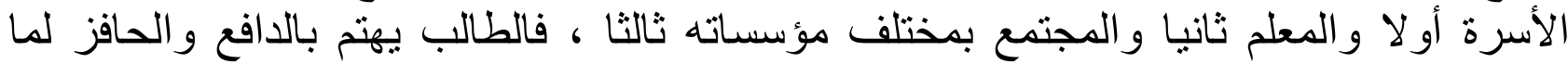

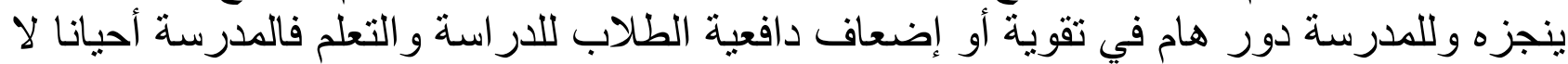

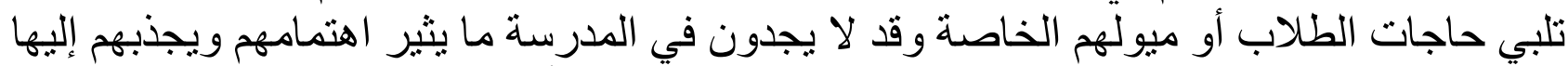

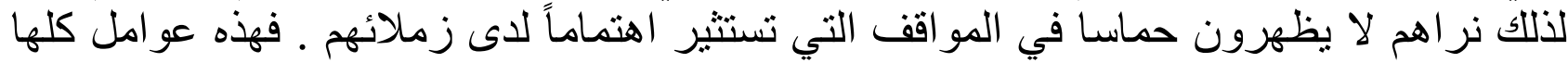

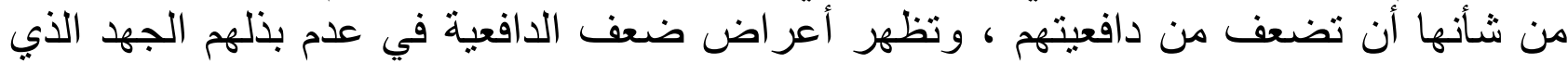

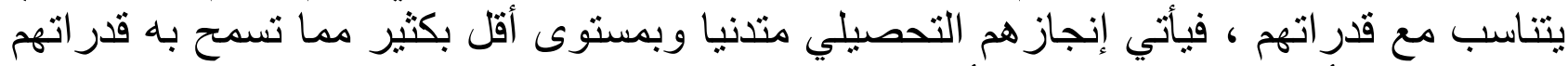

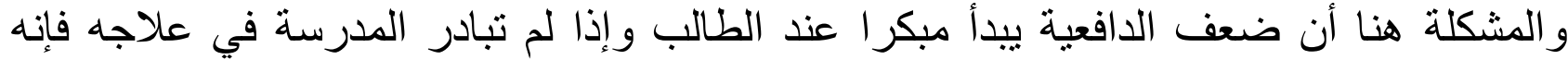

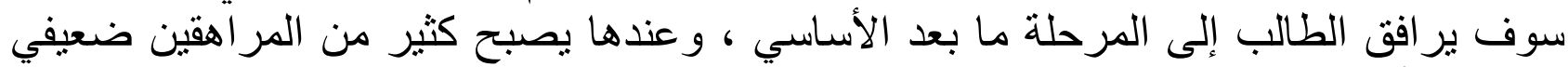

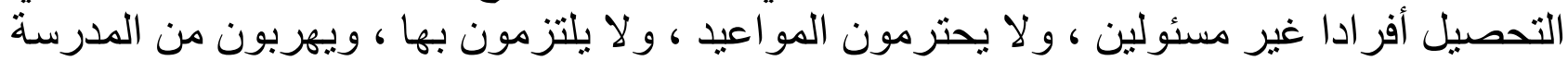

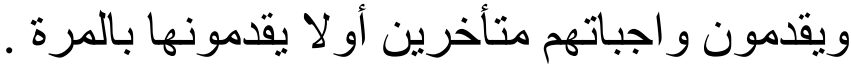

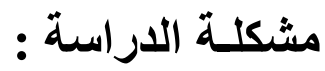

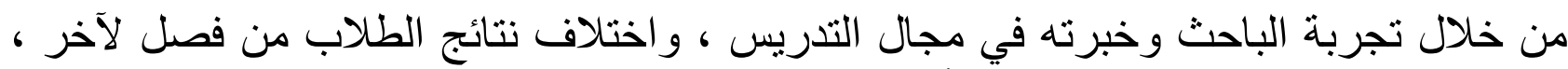

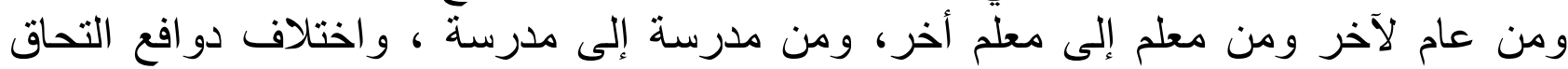

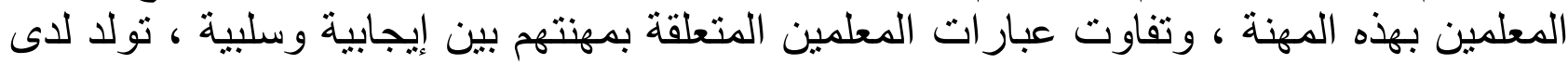

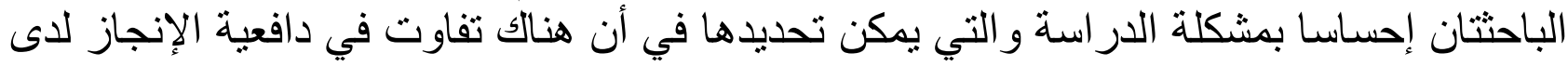

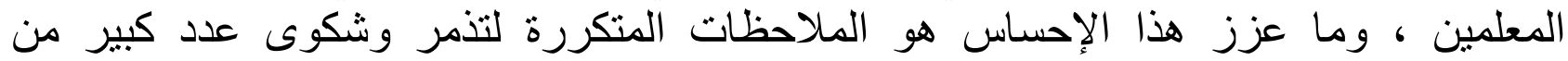

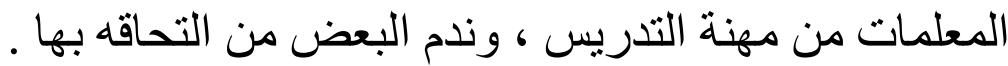

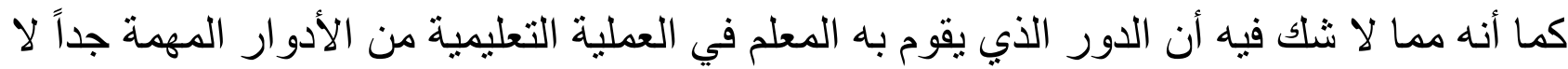

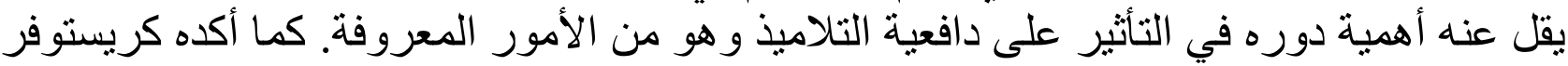

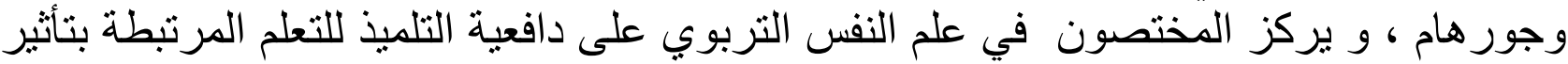

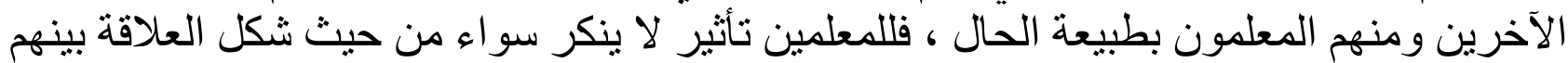

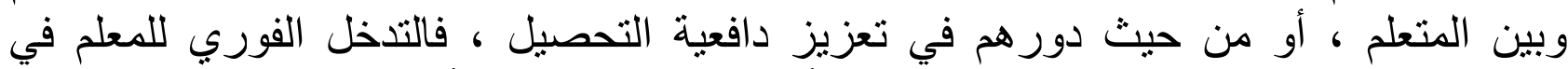

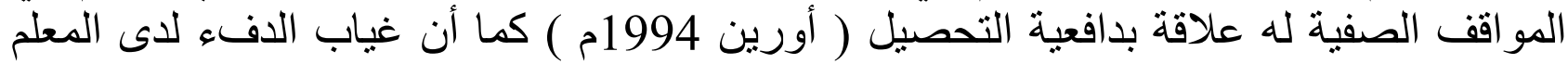

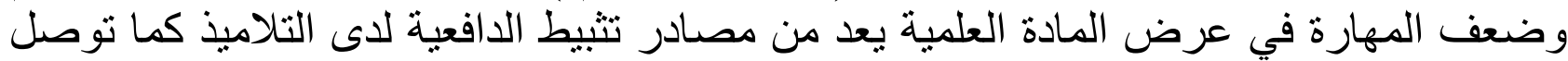

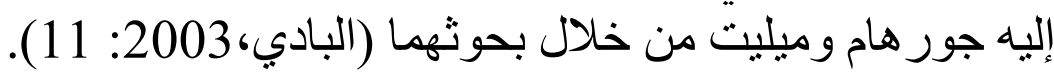

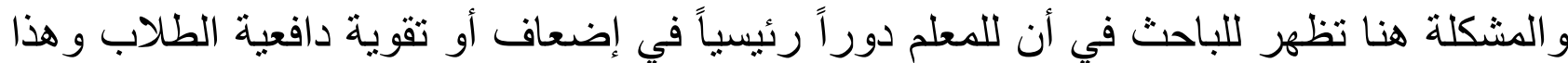

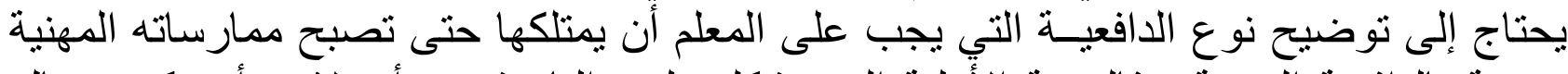

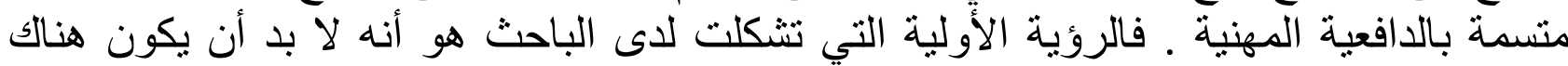

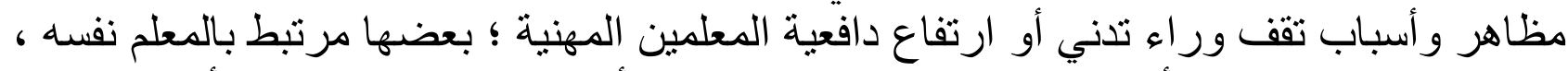

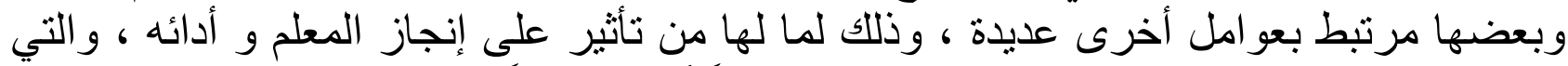

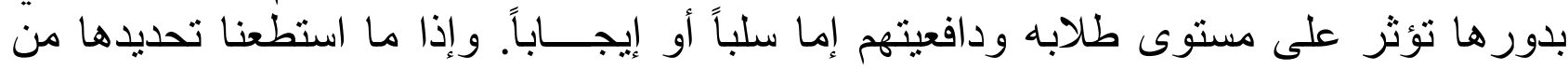

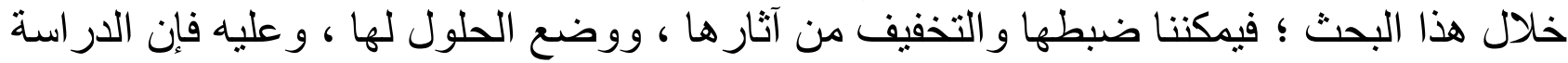
الحالية تسعى للإجابة على التساؤلات الآتية : فلنية 
أهداف اللدراسة:

أ. تشخيص مستوى دافعية المعلمات ومقارنة ذلك بالمستوى التحصيلي للطالبات.

ب. بيان العوامل المدرسية المؤثرة في دافعية المعلم مهنيا. ت. در اسة علاقة عامل الخبرة على دافعية المعلم. ث. معرفة مقترحات المعلمات لتحسين الدافعية المهنية. الار اسات السابقة:

دراسة شواشرة (2007) التي هدفت إلى : معرفة تأثثر برنامج إرشادي في استثارة دافعية

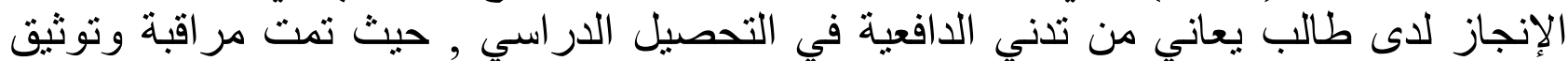

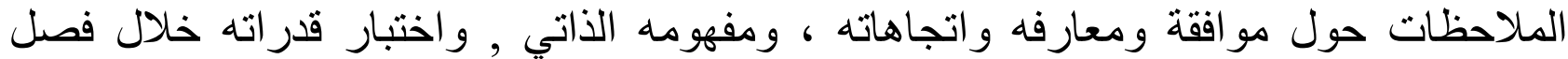

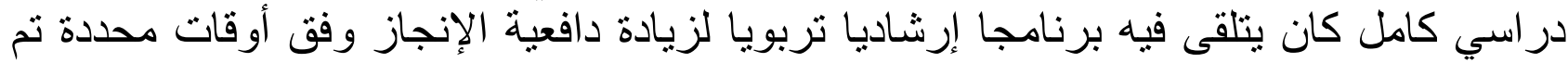
تنفيذه في غرفة الإرشاد التربوي في مدرسنه ـانه

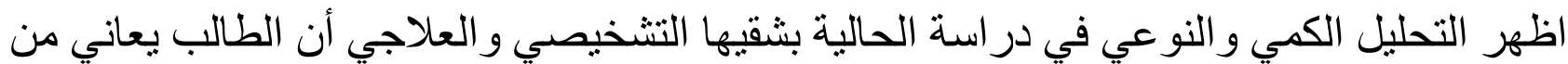

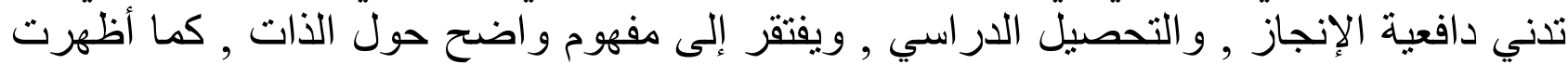
الدراسة أن برنامج الإرشاد التربوي المطبق كان فاعلان في إثارة دافعية الطالب ورفع تحصيله

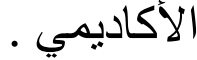

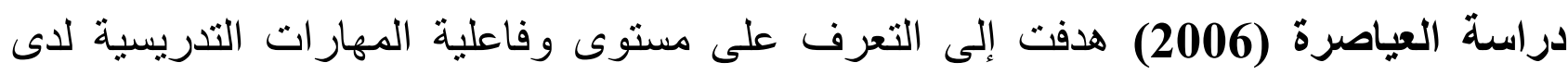

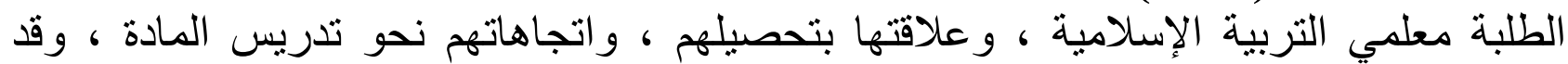

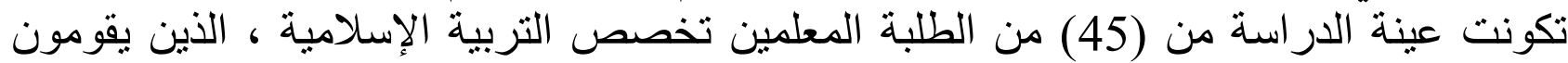

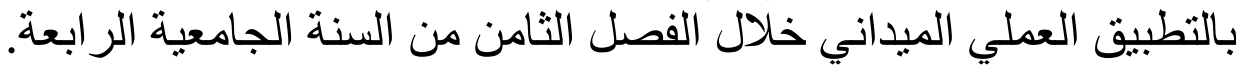

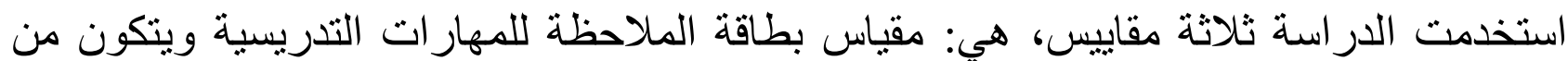

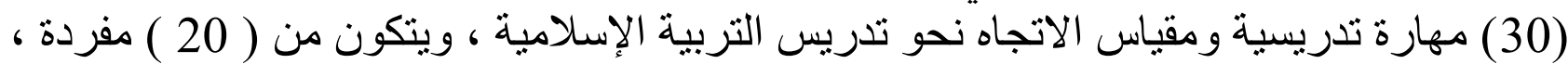

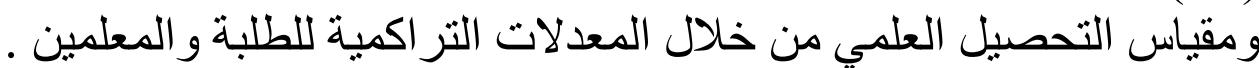

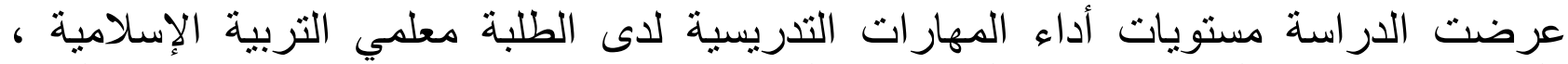

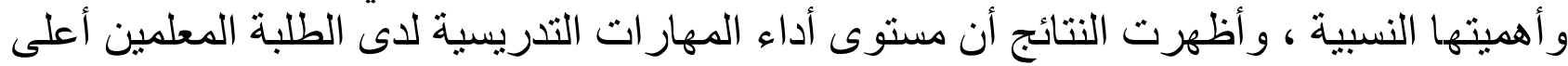

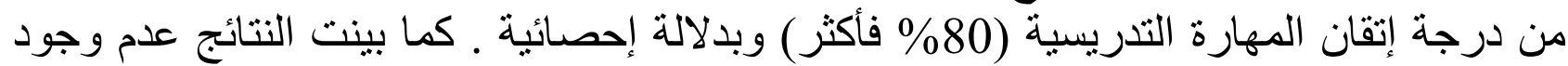

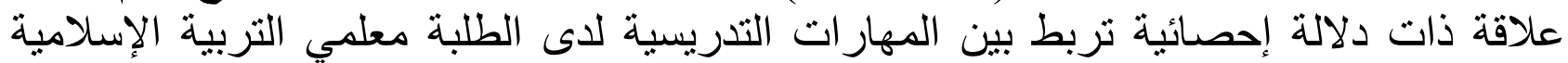

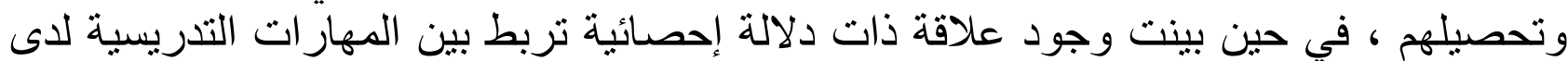
الطلبة معلمي التربية الإسلامية واتجاهاتهم نحو تدريس المادة .

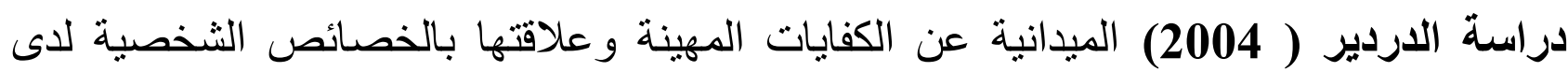

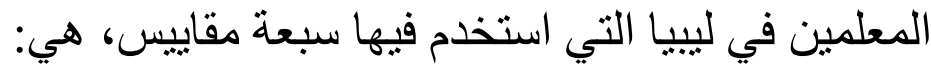
أ. مقياس تقدير الذات من إعداد الباحث ب. مقياس دافعية الإنجاز من إعداد الباحث ت. بطاقة ملاحظة أداء المعلم من إعداد الباحث 
ث. استمارة المؤهل و الخبرة للمعلم من إعداد الباحث. ج. البر وفيل الثخصي لجوردون وجابر عبد الحميد وفؤاد.

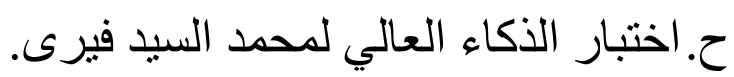

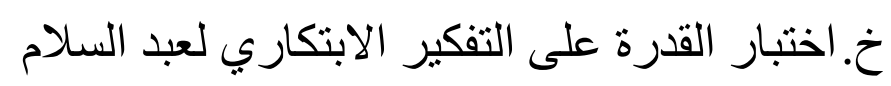

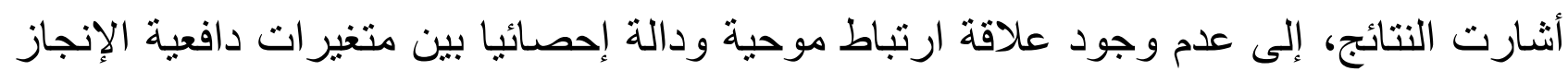

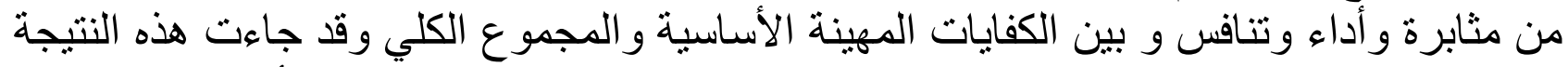

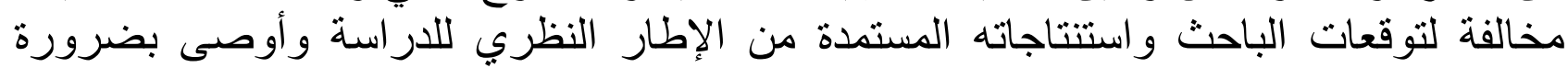

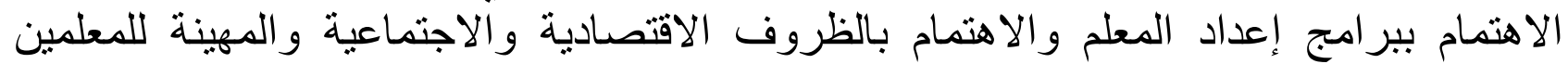

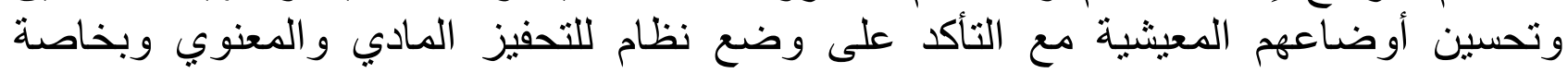

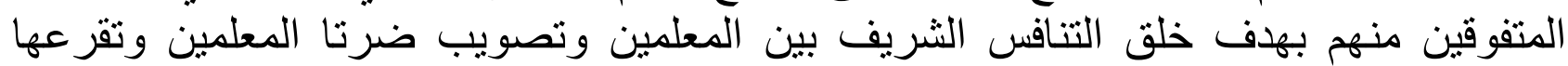

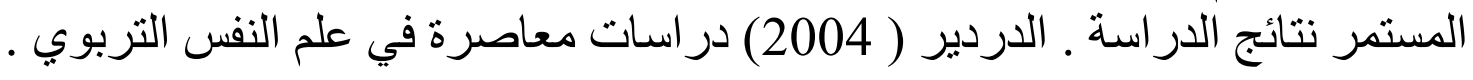
دراسة الهنائية (2007) التي هدفت إلى الكثف عن مستوى إحساس المعلم العماني بكفايته الذاتية

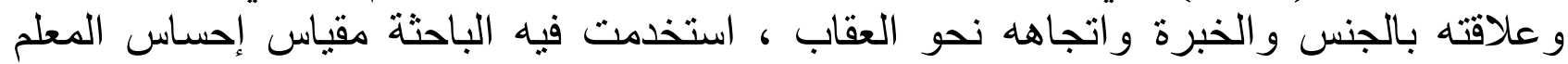

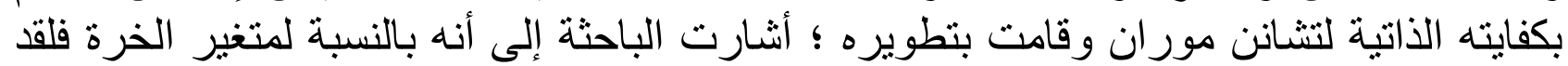

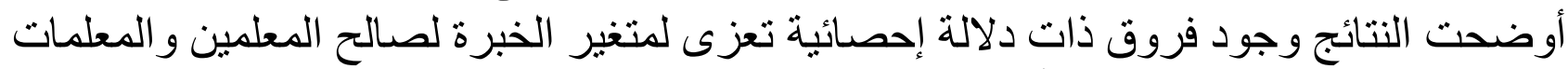

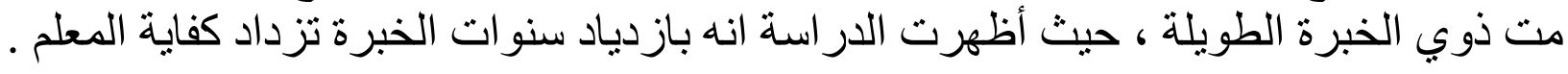

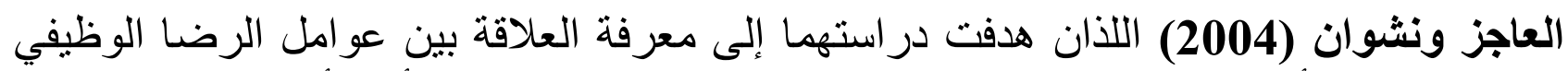

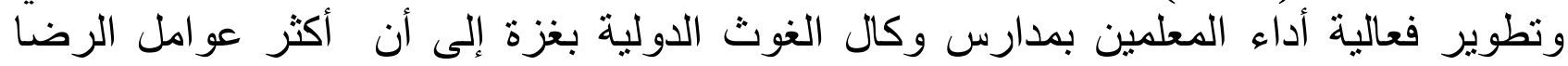

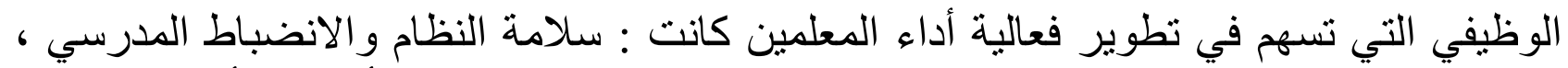

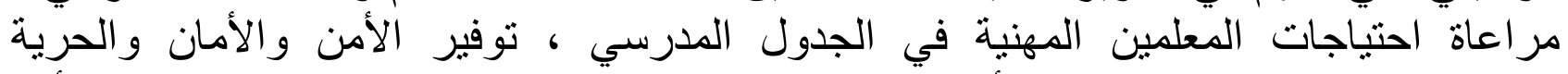

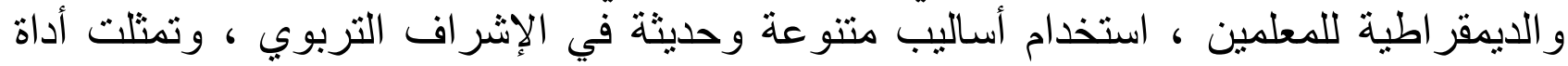

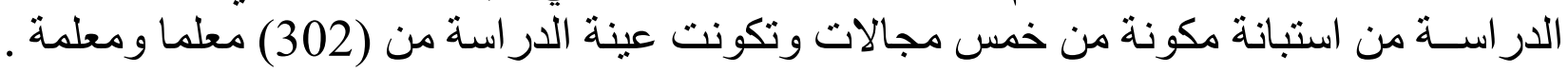

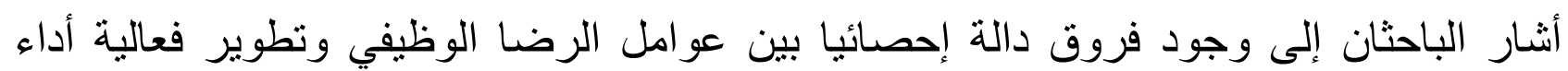

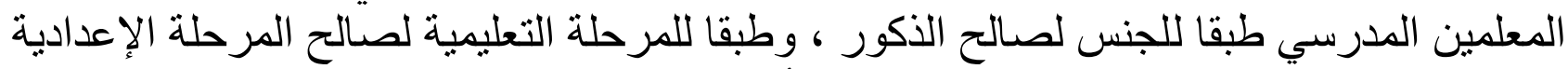

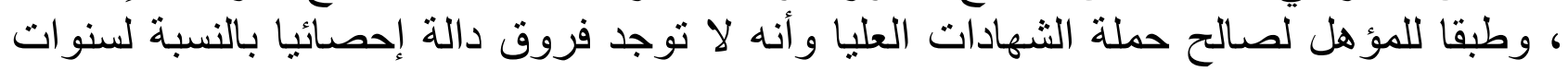
الخدمة (الخبرة).

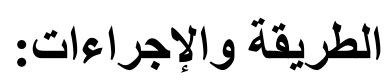

المنهج المستخدم في البحث هو المنهج الوصفي التحليلي، واعتماد المنهج الكمي والنوعي في جمع البيانات.

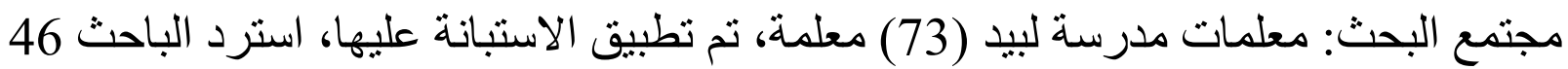
استبانة نم تحليل 21 استبانة منها لربط نتائجها مع نسبة نجاح طلاب كل كل معلمة.

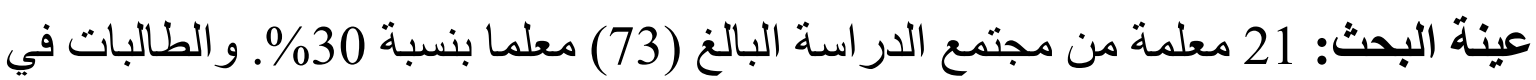

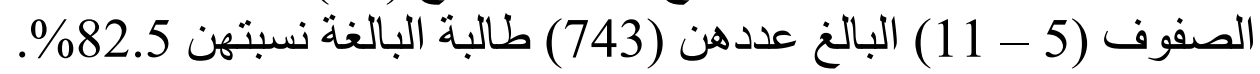


أداتا الار استة: الاستبانة، و المقــابلة.

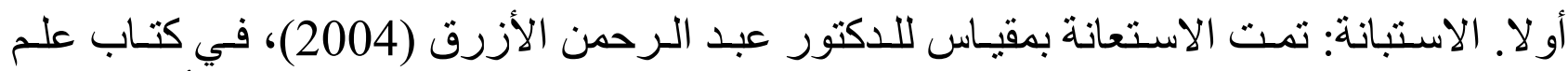

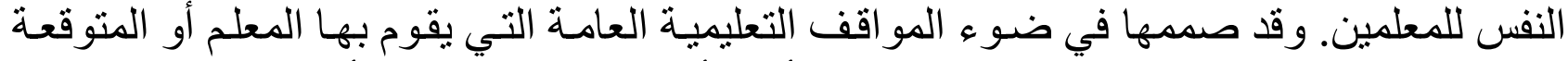

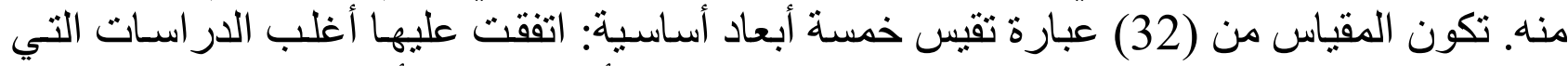

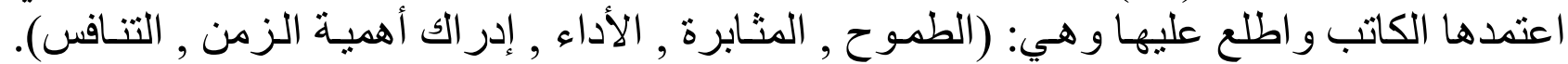

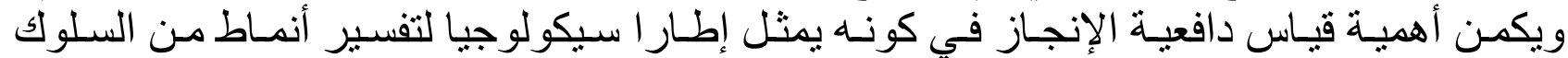

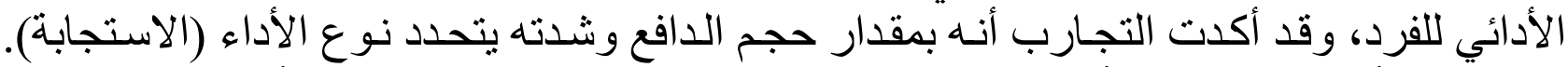

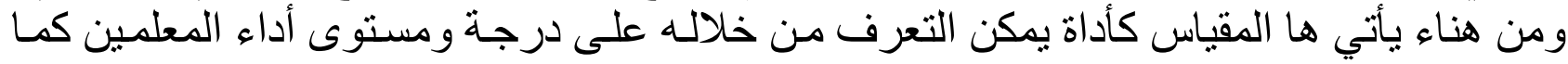
يدركها المعلمون ويحسون بهاء هانيا.

وقد استعان معد الاستبانة عند مراحل بناء المقياس؛ بدراسة وتحليل عدد من التهاء المقاييس، ورزم

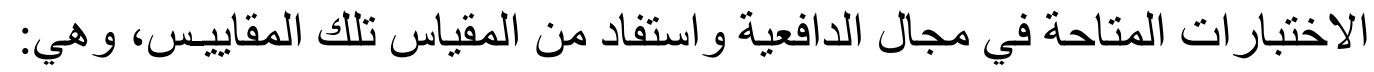
أ. مقياس الدافع للمعرفة و الفهم إعداد ممدوح الكنائس (1990م). ب. مقياس فينر (Weiner, 1990) وقد أعده للاستخدام العربي رشاد عبد العزيز موسى. ت. مقياس أتزنك وويلسون (Essence\& Wilson)ث. مقياس سميث (Smith,1973) لدافعية الإنجاز (منرجم). ج. اختبار هومانس (1990م) لدافع الإنجاز.

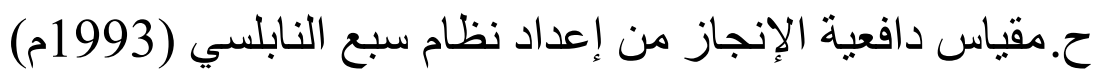

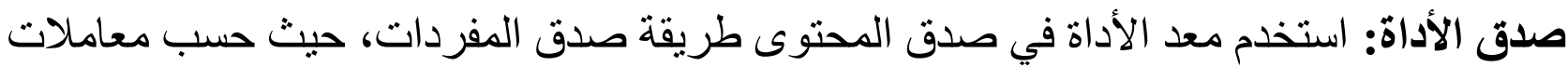

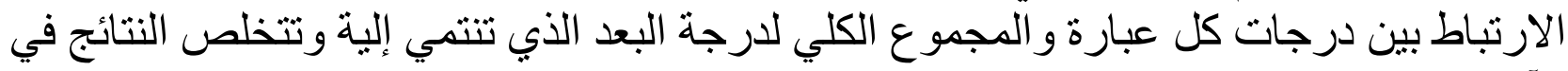

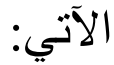

تراوحت معاملات الارتباط جميع العبارات ما بين (0.275 إلى بـ 0.686) و هي جميعها دالة. كما

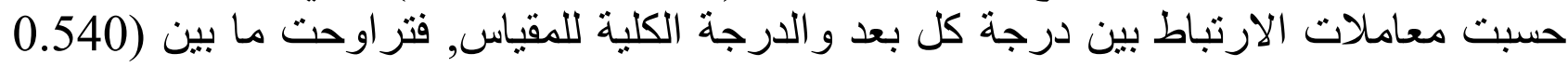

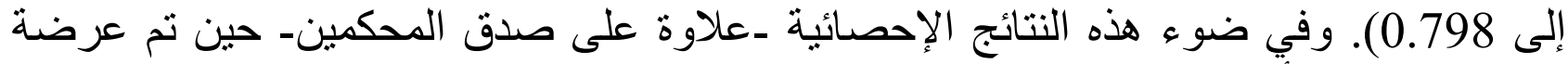

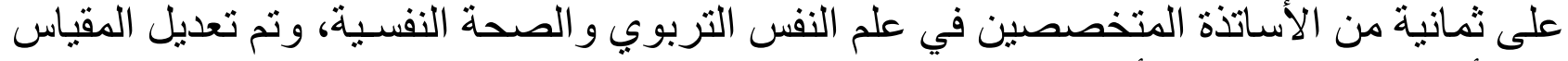

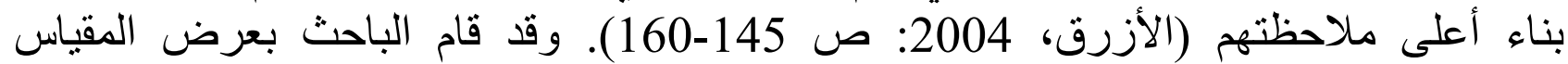

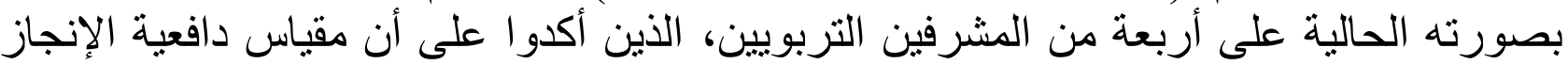

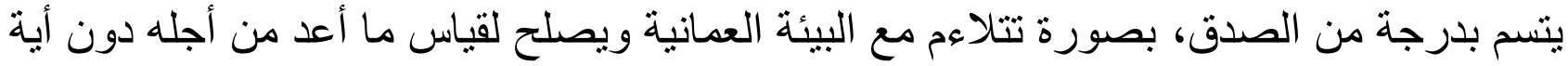

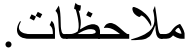

ثبات الأداة: للتحقق من ثبات المقياس استخدمت طريقة التجزئة النصفية بإجر اء معادلة سيبرمان

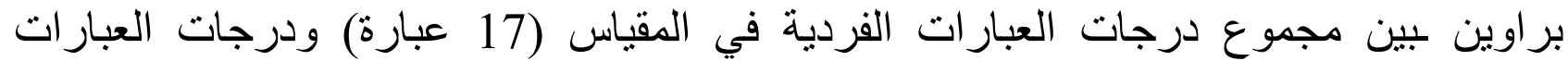

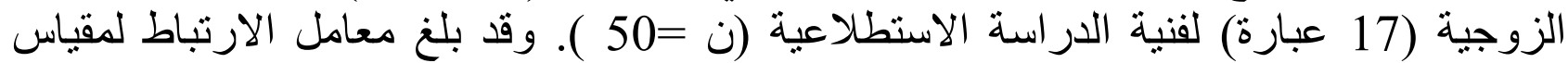

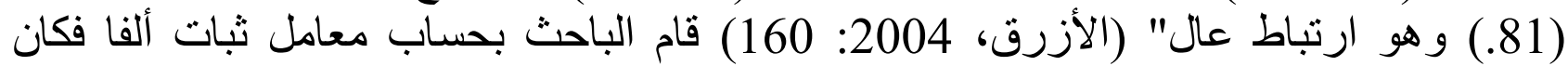

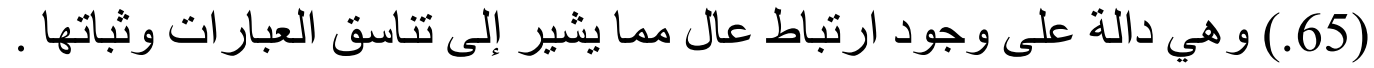




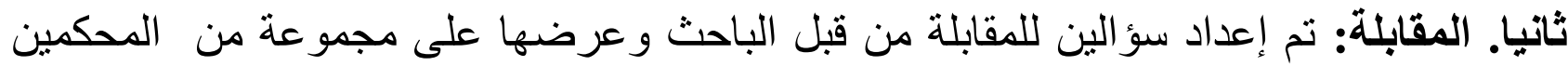

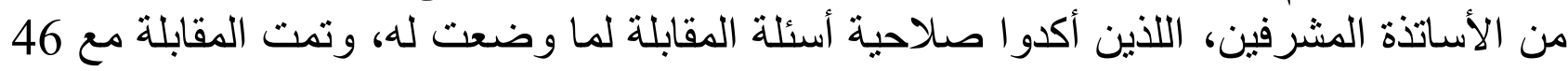
معلما استجاب من العينة 39 معلمة.

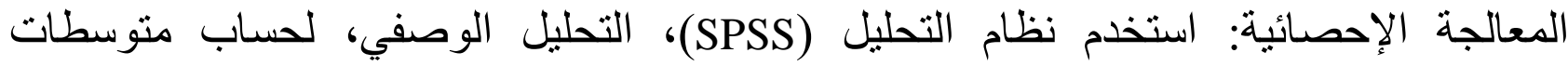

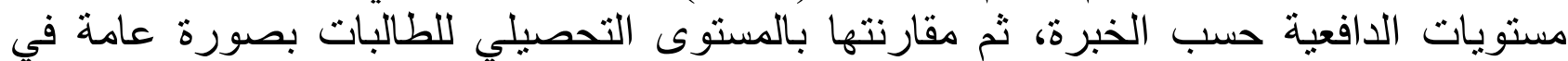

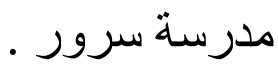

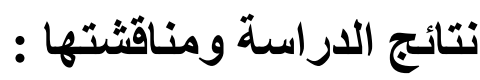

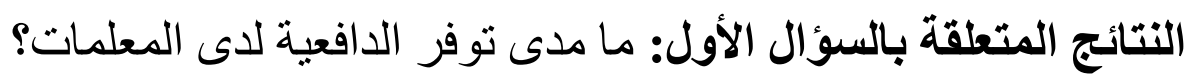
لقياس دافعية المعلمات، قام الباحث بتطبيق وتحليل استبانة (مقياس دافعية الإنجاز ) كالآتي: جدول رقم (1) المتوسطات الحسابية لدافعية المعلمات

\begin{tabular}{|c|c|c|}
\hline الحسبابي & الـعـبـــــــارات & p \\
\hline 4.85 & أشعر بأن الدخول في تحديات مع الآخرين لا طائل من ور اءه & 9 \\
\hline 4.51 & أبذل ما في وسعي أكثر من مرة حتى أحقق أهدافي & 27 \\
\hline 4.42 & كلما حققت هدفا وضعت لنفسي أهدافا أخرى مستقبلية & 23 \\
\hline 4.42 & لا أشعر غالبا بمرور الوقت عندما أكون مشغو لا في عملي & 14 \\
\hline 4.38 & أحرص دائما علي أن يكون وقت العمل في مقدمة اهتماماتي & 17 \\
\hline 4.38 & أسعى دائما إلى إدخال تعديلات مهمة لصآلّ العمل & 3 \\
\hline 4.38 & إذا دعيت لثيء ما أثناء العمل فإني أعود إلى عملي عل الفور & 30 \\
\hline 4.26 & بالتا أتأخر في إنجاز مسؤولياتي على أكمل وجه و إن سمحت الظروف المحيطة & 29 \\
\hline 4.23 & أحب القيام بأي عمل متوقع مني مهما كلفني ذلك من جهد & 1 \\
\hline 4.23 & أشُعر بأنني مجتهد ومثابر في عملي كمدرس & 12 \\
\hline 4.23 & تستهويني الأعمال التي تتسم بجو التنافس و التحدي & 20 \\
\hline 4.2 & كلما وجدت العمل الذي أقوم به صعبا كلما أزداد إصر اري على إنجازه & 10 \\
\hline 4.17 & لا أفكر كثير ا في إنجاز اتي السابقة بل أفكر في التخطيط لإنجاز ات جديدة & 16 \\
\hline 4.17 & لا أعتقد أن مستقبلي سيكون مر هونا بظروف الحظ و الصدفة & 8 \\
\hline 3.93 & لي أحرص على الاشتر الك في المسابقات ذات الصلة بمجالات اهتماماتي كلما أتيحت & 18 \\
\hline 3.76 & أجتهد دائما في عملي لأتفوق على من أعمل معهم & 5 \\
\hline 3.71 & أستعد دائما لأذّاء الأعمال الصعبة التي تتطلب مجهودا في تحقيقها & 21 \\
\hline 3.46 & متاعيل أحيانا إلى التر اجع عن مو اقفي أمام الخصوم إذا كان الإصر ار يسبسب لي & 15 \\
\hline 3.36 & أستطيع أداء نفس العمل لساعات طويلة دون الثعور بالملل & 2 \\
\hline 3.36 & لا أميل إلى الاعتقاد بالر أي القائل ( كن أو لا تكن ) & 25 \\
\hline 3.36 & أشتعر بالضيق من ضعف كفاءتي في العمل & 28 \\
\hline 3.15 & أعتقد أن وضعي الحالي أفضل ما يمكن الوصول إليه & 11 \\
\hline 3.1 & أشعر باليأس أحيانا في إيجاد الحلول للمصاعب التي تعترض حياتي & 24 \\
\hline 2.97 & كثير ا ما تمر الأيام دون أن أعمل شيئًا بذكر & 4 \\
\hline
\end{tabular}




\begin{tabular}{|c|c|c|}
\hline 2.88 & غالبا ما أؤجل عمل اليوم إلى الغد & 22 \\
\hline 2.72 & كثير ا ما أشُعر بعدم قدرتي على القيام بما و عدت به سابقا & 26 \\
\hline 2.63 & أنسحب غالبا بسهولة عندما تو اجهني مشاكل صعبة في عملي & 19 \\
\hline 2.59 & لم أعد أحتمل المصاعب الكثيرة التي تو اجهني في أداء عملي & 32 \\
\hline 2.5 & أتجنب غالبا القيام بالمهام و المسؤوليات الصعبة في عملي & 13 \\
\hline 2.38 & أعتقد بأنني شخص يكتفي بالقليل من الآمال و الطموح . & 6 \\
\hline 2.2 & أفضلف تأدية عملي بمستوى متوسط من الإتقان إذا كان تحقيق المستوى الأعلى & 7 \\
\hline 1.95 & أهدافي أفكر كثير ا في البحث عن طرق أخرى بديلة عندما تفشل الطرق السابقة في بلوغ & 31 \\
\hline
\end{tabular}

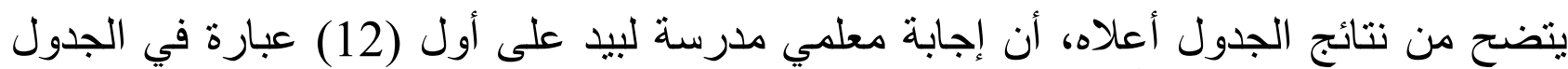

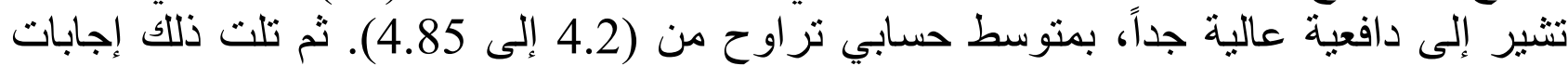

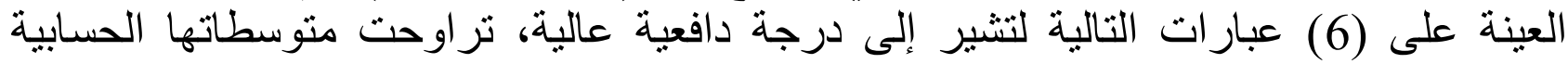

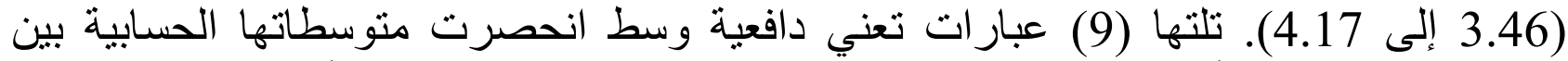
(2.63 إلى 3.36). و أخيرا (5) (9.36) عبار ات تشير إلى دافي دافية واطئة. ولم تحصل أية عبارة على تقدير

ولمعرفة ما إذا كان هناك أثر لهذه الدافعية على المستوى التحصيلي للطلاب؛ قام الباحث بتحليل

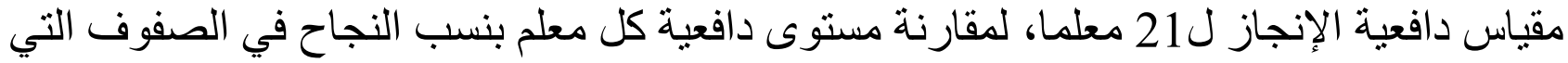
يقوم بتدريسها ؛ كما يتضح من الإن الجدول الآتي: جدول:رقم (2) علاقة مستوى دافعية المعلمين بالمستوى التحصيلي لطلابهن

\begin{tabular}{|c|c|c|}
\hline نسبة نجاح طلاب المعلم & مستوى & نسبة دافعية المعلم \% \\
\hline 95.6 & عالية جداً & 94.7 \\
\hline 72.2 & عالية جداً & 90.6 \\
\hline 100 & عالية جداً & 86.4 \\
\hline 100 & عالية جداً & 85.4 \\
\hline 92.4 & عالية جداً & 84.3 \\
\hline 95.3 & عالية جداً & 84.3 \\
\hline 81.5 & عالية جداً & 84.3 \\
\hline 78.9 & عالية جداً & 83.3 \\
\hline 91.5 & عالية جداً & 81.2 \\
\hline 81.8 & عالية جداً & 80.2 \\
\hline 72.8 & عالية جداً & 80.2 \\
\hline 91.5 & عالية & 79.1 \\
\hline 74.2 & عالية & 79.1 \\
\hline 100 & عالية & 78.1 \\
\hline 58.6 & عالية & 78.1 \\
\hline 90.9 & عالية & 73.9 \\
\hline 92 & عالية & 73.9 \\
\hline
\end{tabular}




\begin{tabular}{|l|c|c|}
\hline 78.7 & ع مالية & 71.8 \\
\hline 90.2 & 68.7 \\
\hline 94.5 & متوسطة متوسطة & 67.7 \\
\hline 94.5 & متوسطة & 64.5 \\
\hline
\end{tabular}

نلاحظ من خلال الجدول، أنه لا يوجد أثر لمستوى دافعية المعلم على نسب نجاح الطلاب. فئي

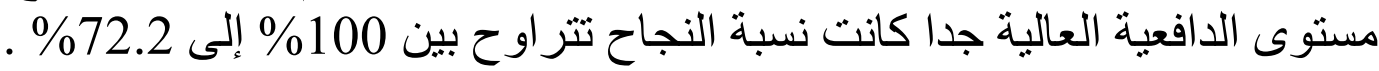
وفي مستوى الدافعية العالية تر اوحت نسبة نجاح الطلاب بين 100\% و 58.6 \% \% م بينما كانت نسب نجاح الطلاب مرتفعة لم تقل عن 90 \% عند المعلمين ذوب الدافعية المتوسطة .

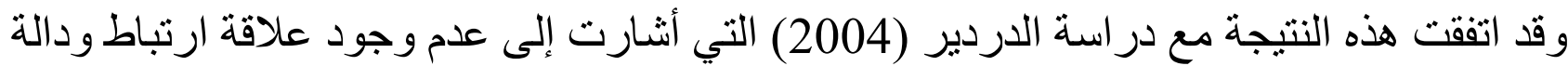

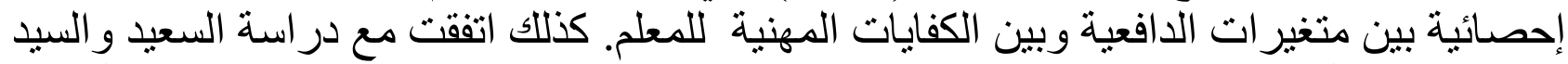

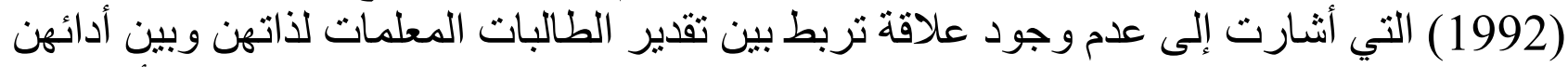

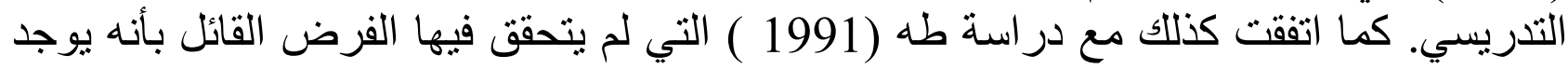

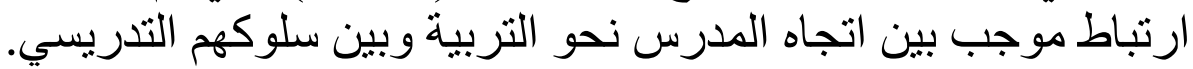

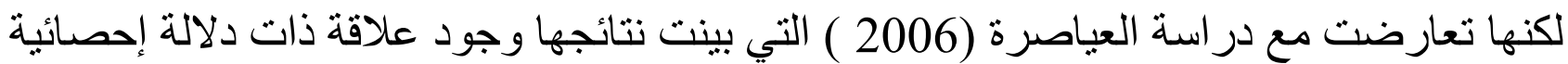

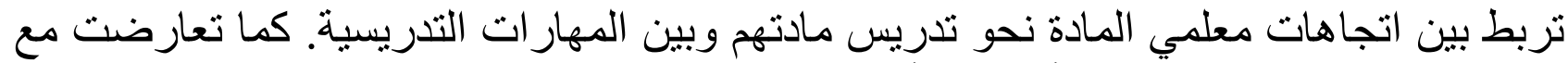

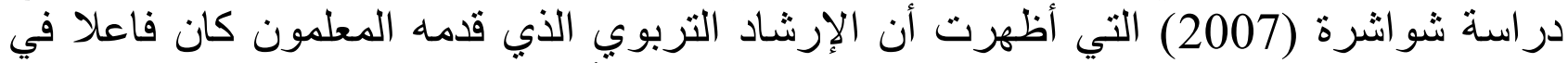

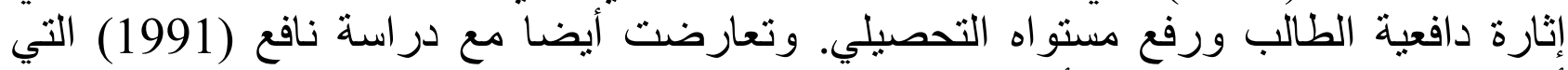

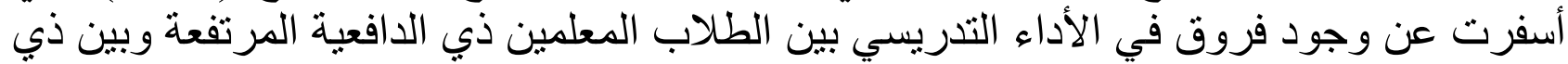

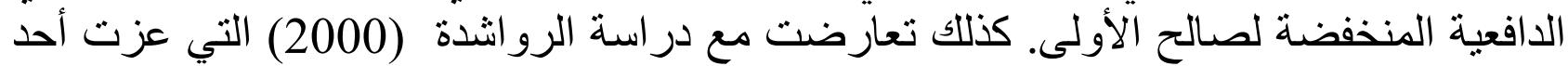

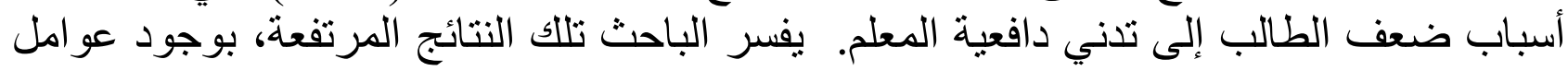
كتبرة ساهدت في ارتفاع نسب نجاح الطلاب: كالترفيع التلقائي، وسهولة المادة، ومستوى دافعية الفية الطلاب.

\section{التتائج المتعلقة بالسؤال الثاني:}

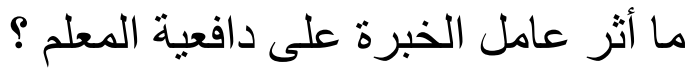
يوضح الجدول التالي توزيع المعلمين (عينة الدراسة) بين سنوات الخبرة ، مقسمة إلى ثلاث فئات فئة (1 - 4) سنو ات، وفئة (5 - 9) سنو ات، وفئة (10) سنو ات فما فوق: جدول رقم (3) عدد المعلمين في مدرسة لبيد بالنسبة لمتغير سنوات الخبرة

\begin{tabular}{|c|c|}
\hline سنوات الخبرة & \\
\hline 82.4 & $4-1$ \\
\hline 78 & $9-5$ \\
\hline
\end{tabular}


كما نلاحظ في الجدول أعلاه، يتضح من نتائج الدراسة والتحليل الإحصائي لسنوات الخبرة

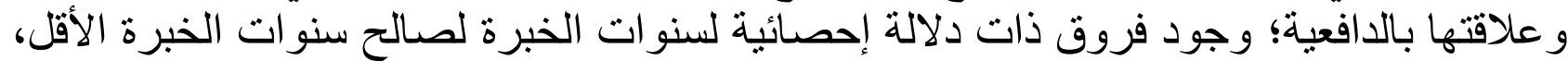

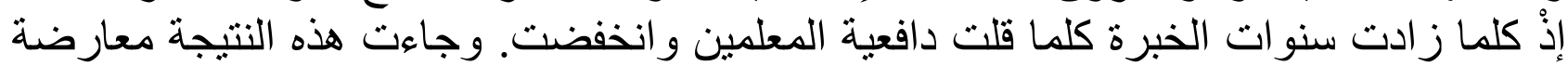

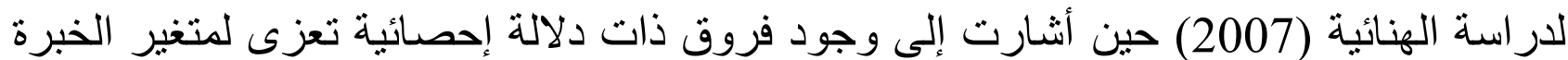

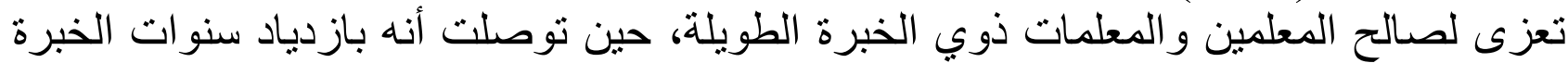

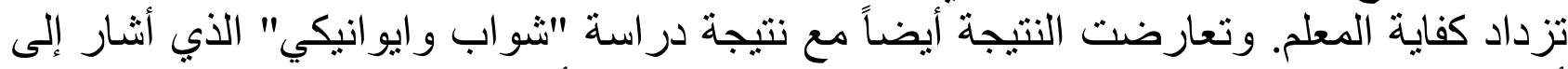

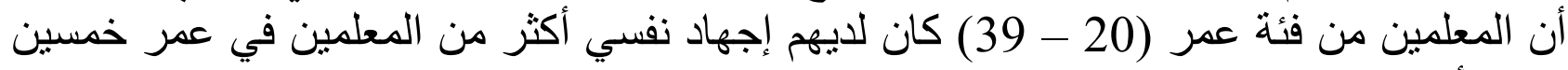
عاما فأعلى.

في حين جاءت النتيجة موافقة للار اسة الموسومة: (أثر التخصص وسنواتوات الخبرة في اتجاهات

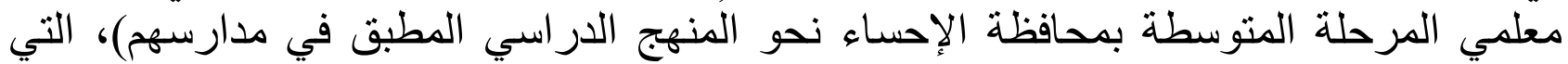

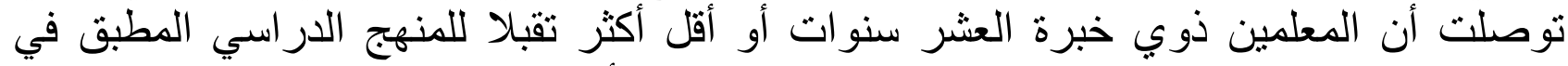

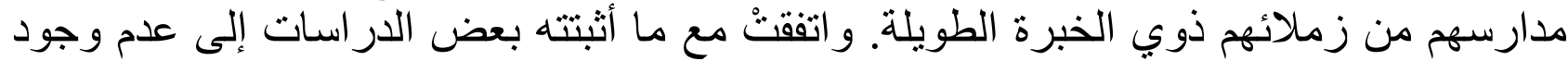

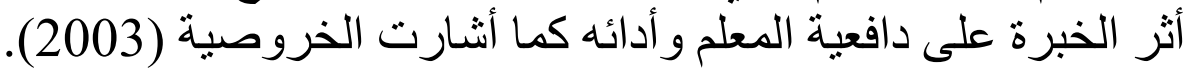

النتائج المتعلقة بالسؤال الثالث: ما العو امل المدرسية المؤثرة في دافعية المعلم مهنيا؟ تمت الإجابة عن هذا السؤ ال من خلال مقابلة أجر اها الباحث مع 39 معلما، كما يظهر من الجدول دئه دئه الآتي :

جدول رقم (4) العو امل المدرسية المؤثرة في دافعية المعلمين

\begin{tabular}{|c|c|}
\hline المتوسط الحسابي & 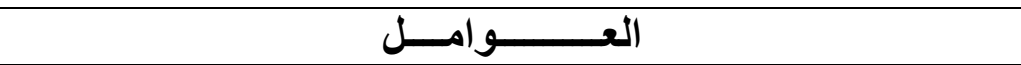 \\
\hline 51.3 & كثرة الأعمال الملقاة على عاتق المعلم \\
\hline 43.6 & ندرة التشجيع والتحفيز من الإدارة \\
\hline 15.4 & ضعف مستو يات الطلاب المعرفية \\
\hline 12.9 & كثافة بعض المناهج \\
\hline 12.9 & عدم توفير الإمكانيات و الوسائل اللازمة \\
\hline 10.2 & كثرة الحصص \\
\hline 10.2 & قلة الحو افز المادية و المعنوية \\
\hline 10.2 & الإحباط الذي يتعرض له المعلم أثناء تأدية عمله \\
\hline 10.2 & عدم اهتمام الطالبات بتحسين مستو اهن التحصيلي \\
\hline 8.2 & عدم إحساس الطلاب بالمسؤولية \\
\hline 8.2 & ضعف التعاون بين أفراد المجمو عة الو احدة \\
\hline 7.1 & عدم تقبل المعلم للمادة كما هو الحال في مادة منهج البحث \\
\hline 7.1 & عدم احتر ام الطالبات للمعلمات \\
\hline 2.6 & عدم مرونة الإدارة مع المعلم \\
\hline 2.6 & الرسائل السلبية التي تبعث للمعلم أثناء الاجتماعات وتعميم السلبيات \\
\hline
\end{tabular}

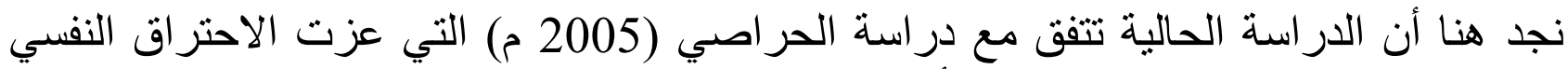
للمعلم إلى ضنغوط المن المهنة في المرنبة الأولى. 


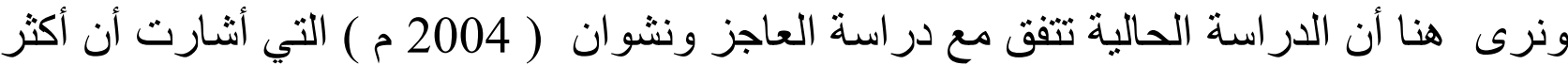
العو امل المسببة للرضا الوظيفي والتي تسهم في تطوير فعالية الدية المعلم هي مراعاة احتياجات

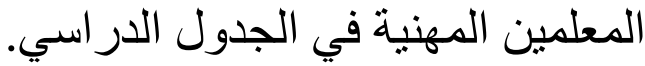

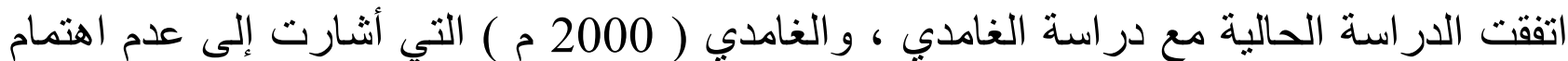

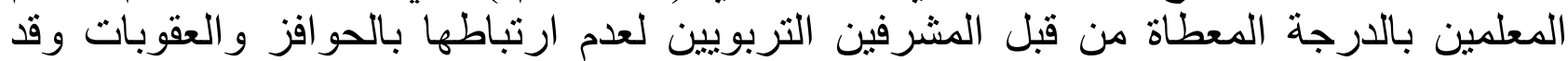

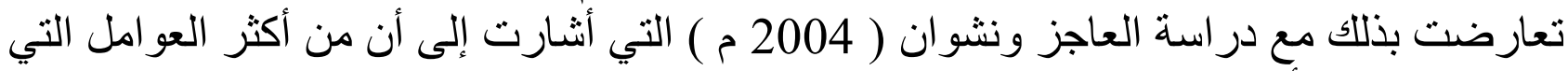

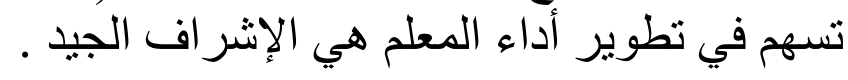

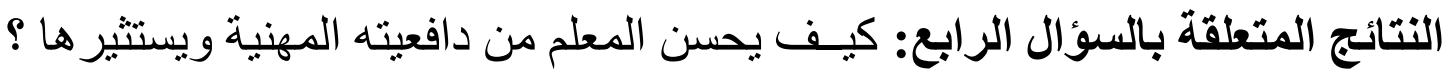

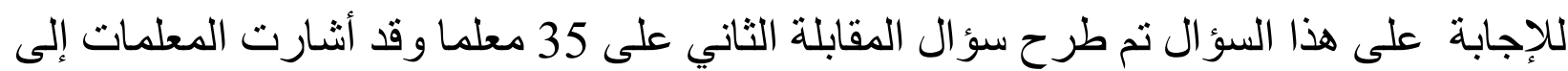

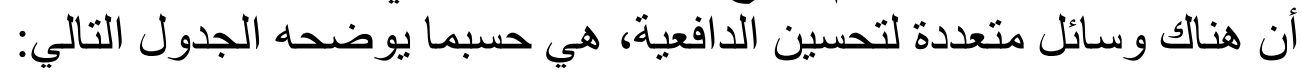

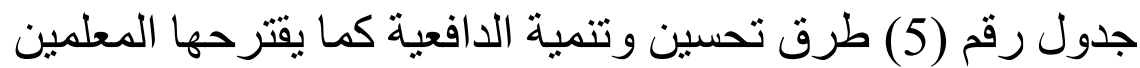

\begin{tabular}{|c|c|}
\hline النسبة المئوية \% & طرق تحسين وتنمية الدافعية كما يقترحها المعلمين \\
\hline 34.3 & الاطلاع على أحدث الطرق \\
\hline 31.4 & تذليل العو ائق و الصعوبات ، تنمية الروح الإيجابية \\
\hline 22.9 & الاطلاع و القر اءة على كل ما هو جديد في علوم التربية \\
\hline 8.5 & الإخلاص في العمل \\
\hline 8.5 & التعاون بين أفر اد المجمو عة \\
\hline 8.5 & محاولة تحسين مسنوى الطالبات \\
\hline 8.5 & التوكل على الله \\
\hline 8.5 & تحديد الأهداف \\
\hline 8.5 & الحرص على تحقيق الأهداف \\
\hline 8.5 & إعطاء المعلم نفسه رسائل إيجابية \\
\hline 5.7 & حضور المشاغل التربوية \\
\hline 5.7 & عدم التباطؤ في إنجاز الأعمال مهما كانت الظروف \\
\hline 2.9 & حب المعلم للمادة التي يدرسها \\
\hline 2.9 & وضع برامج من قبل الإدارة لإظهار بعض أنشطة المعلمين \\
\hline 2.9 & رغبة المعلمين وقت لمناقثشة المعلمـات لبعض الأمور المستجدة حسب \\
\hline 2.9 & تحسين العلاقة مع الإدارة \\
\hline 2.9 & ابتكار طرق تربوية جديدة للتعامل مع الطلاب \\
\hline 2.9 & تنظيم الوقت \\
\hline 2.9 & الحرص على التفوق في العمل \\
\hline
\end{tabular}

نلاحظ من الجدول السابق أن أغلب المعلمين أشاروا إلى الطرق التالية لتحسين الدافعية:

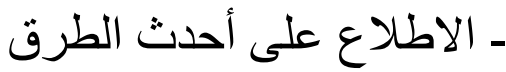
ـ تذليل العو ائق و الصعوبات، تنمية الروح الإيجابية، والاطلاع و القراءة على كل ما هو جديد في

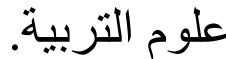
- بينما أثنارت فئة بسيطة من المعلمات لضرورة تنظيم الوقت وحب المهنة وابتكار طرق ثربوية، 
على الرغم من أهميتها، وقد يعود ذللك لعدم تثقيف المعلمات أنفسهن بالاطلاع على ما هو جديد من

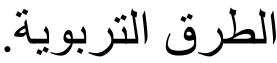

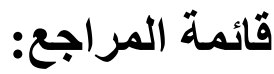

الأزرق ، عبد الرحمن بن صالح (2000) علم النفس التربوي للمعلمين ، لبنان : دار الفكر العربي.

البادي ، نورة بنت سالم بن سيف (2003) أساليب استثارة الدافعية : المشاركات المتميزة في المئي الملتقيات السنوية للمعلمين المعقودة في العامين 2 / 2003 و 3 / 2004.

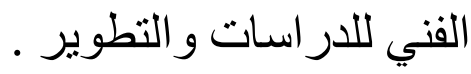

جابر ، جابر عبد الحميد (2000) مدرس القرن الحادي والعشرين الفعال : المهارات والتنمية المهنية ، القاهرة : دار الفكر العربي .

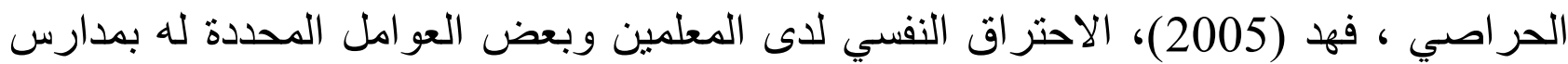

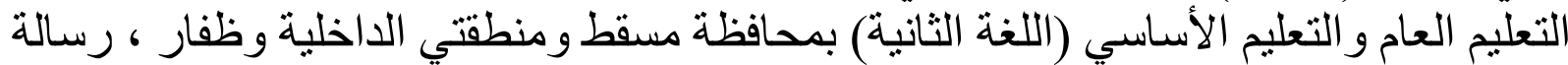

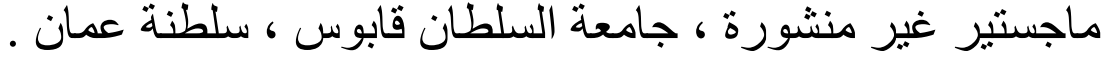
الخروصية ، ميمونة بنت محمد بن حارث (2003)مدى استخدام معلمات التربية الإسـلامية بالحلقة

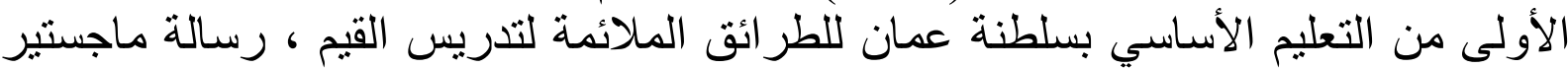

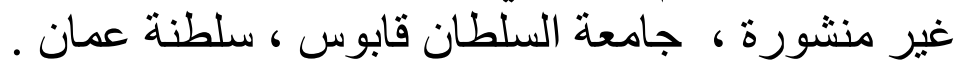

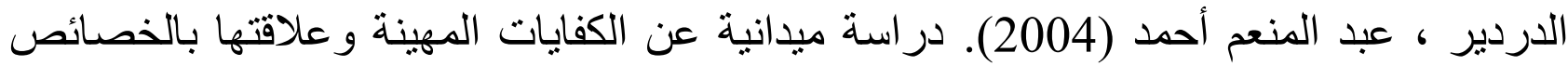

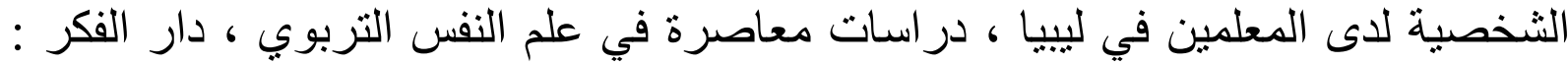
لبنان . شحاتة، حسن (1994). المعلمون والمتعلمون : أنماطهم وسلوكهم وأدوار هم ، القاهرة : مكتبة

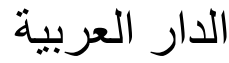

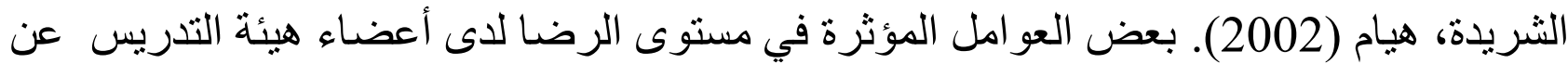

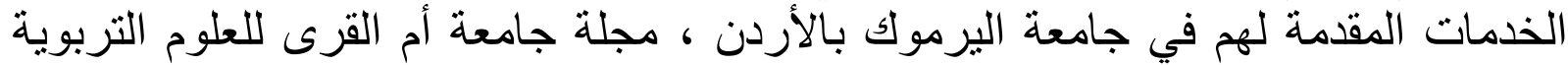

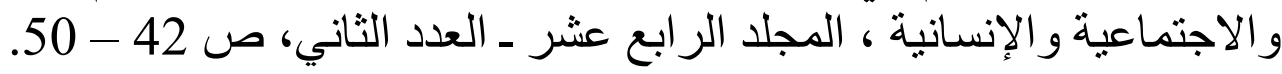
شو اشرة، عاطف حسن (2007) فاعلية برنامج في الإرشاد التربوي في استثارة دافعية الإنجاز لدى طالب يعاني من تدني الدافعية في التحصيل الدراسي: دراسة حالة الأة. الأردن: (د .ن).

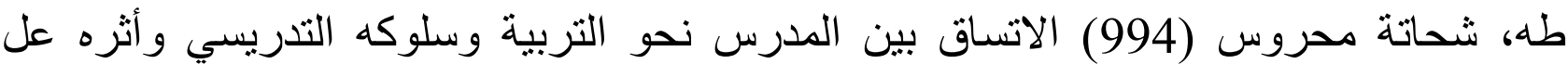

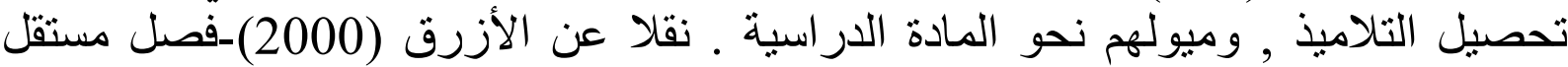
لعرض در اسات تربوية . تونئ.

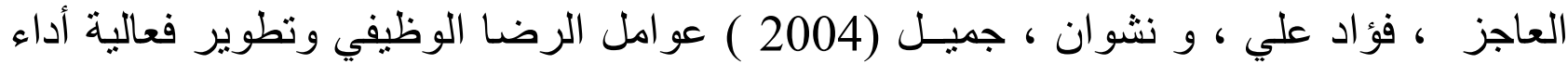
المعلمين بمدارس وكالة الغوث الدولية بغزة ، بحث مقدم على المؤتمر التربوي الأول / 


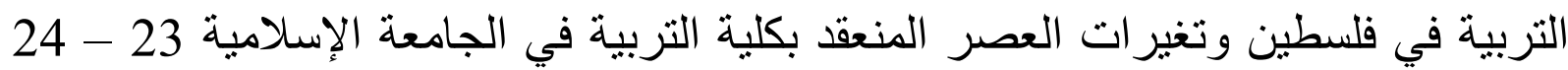

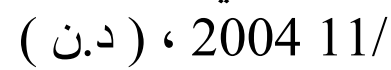

عبد الله ، منصور (2004 ) : وجهة الضبط لدى معلمي وتلاميذ المرحلة الابتدائية وعلاقتها

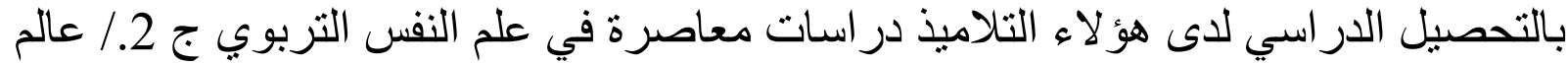

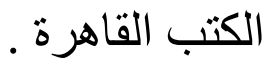

عدس ، محمد عبد الرحيم ( 2002 ) تدني الإنجاز المدرسي : أسبابه و علاجه ، ط2 ، عمان : دار الفكا

العويسي ، رجب (2003) ، التدريس وتجديد طاقات المعلم ، مجلة التطوير التربوي ، العدد 33 ـ

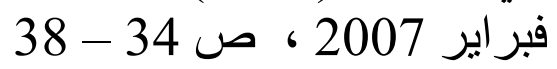

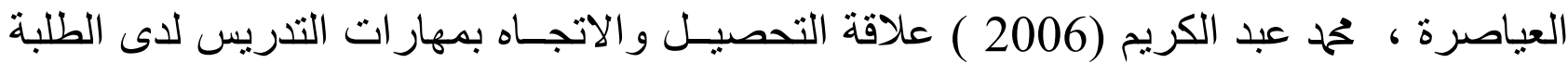

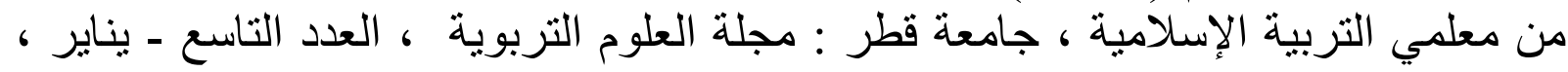

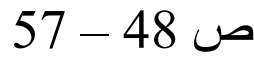

نافع ، سعيـد عبـده. (1991): أثر التفاعل بين مستوى دافعية الإنجاز ومفهوم الذات على الأداء

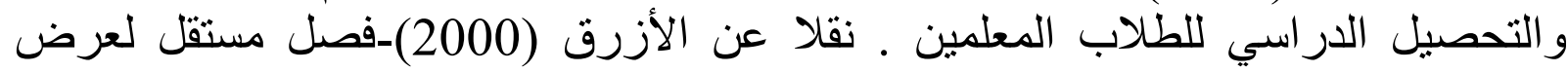

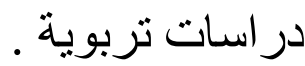

الهنائية ، خلود ( 2006) الكفاية الذاتية لمعلمي ومعلمات الحلقة الثانية من التعليم الأساسي لهابي و علاقتها بالجنس و الخبرة و اتجاهاتهم نحو العقاب في مسقط ، رسالة ماجستير غير منشورة ، مسقط : جامعة السلطان قابوس.

\section{ARABIC REFERENCES IN ROMAN ALPHABET}

Al'azraq, Eabd Alruhmin Bin Salih (2000) Eilm Alnafs Alturbuiu Lilmuelimin, Lubnan : Dar Alfikr Alearabi. Albadi,

Nurat Bnt Salim Bin Sayf (2003) 'Asalib Aistitharat Alddafieiat: Almusharakat Almutamayizat Fi Almultaqayat Alsanawiat Lilmuealimin Almaequdat fi Aleamayn 2 / 2003 W 3 / 2004. Masqat: Almaktab Alfaniyi Lildirasat Waltatwir.

Jabir, Jabir Eabd Alhamid (2000) Mudaris Alqarn Alhadi Waleishrin Alfaeeal : Almaharat Waltanmiat Almihniat, Alqahrt : Dar Alfikr Alearabia .

Alharasiu, Fahd (2005), Alaihtiraq Alnafsiu Ladaa Almuealimin Wbed Aleawamil Almuhadadat Lah Bimadaris Altaelim Aleami Waltaelim Al'asasii (Allughat Alththania) Bimuhafazat Masqat Wamintaqati Alddakhiliat Wazifar, Risalat Majstyr Ghyr Manshurat, Jamieat Alsultan Qabws, Saltanatan Eamman .

Alkhurusiat, Mymwnt Bnt Muhamad Bin Harith (2003) Madaa Aistikhdam Muealamat Altarbiat Al'islamyat Bialhulqat Al'uwlaa Min Altaelim Al'asasii Bisaltanat Eamman Liltarayiq Almulayimat Litadris Alqiam, Risalat Majstyr Ghyr Manshurat , Jamieat Alsultan Qabws , Saltanatan Eamman

Aldardir, Eabd Almuneim 'Ahmad (2004) Dirasatan Maydaniatan Ean Alkifayat Almahinat Waealaqatiha Bialkhasayis Alshakhsiat Ladaa Almuealimin fi Libia, Dirasat Mueasiratan fi Eilm Alnafs Altarbuii , Dar Alfikr : Lubnan .

Shahatatan, Hasan (1994). Almuelamun Walmutaealimun: 'Anmatuhum Wasulukuhum Wa'adwaruhum, Alqahrt: Maktabat Aldaar Alearabia

Alsharidat, Hiam (2002). Bed Aleawamil Almuatharat fi Mustawaa Alridda Ladaa 'Aeda' Hayyat Altadris Ean Alkhadamat Almuqadamat Lahum fi Jamieat Alyarmuk Bial'urduni , Majalat Jamieatan 'Ama Alquraa Lileulum Altarbawiat Walaijtimaeiat Wal'iinsaniat, Almujalid Alrrabie Eshr Aleadad Alththani, S 42 - 50

Shawashirat, Eatif Hasan (2007) Faeiliatan Barnamaj fi Al'iirshad Altarbuii fi Aistitharat Dafieiat Al'iinjaz 
Ladaa Talab Yueani min Tadaniy Alddafieiat fi Altahsil Aldirasii Dirasatan Halatan, Al'urdun: (D.N).

Tah, Shihatat Mahrus (994) Alaitisaq Bayn Almudris Nahw Altarbiat Wasulukih Altadrisii Wa'athrah El Tahsil Altalamidh, Wamuyulihim Nahw Almadat Aldirasia . Naqlaan Ean Al'azraq (2000)-Fusul Mustaqilin Lieard Dirasat Tarbawia.

Aleajiz, Fuad Eali, W Nashwan, Jumyl (2004) Eawamil Alrida Alwazifii Watatwir Faeealiat 'Ada' Almuealimin Bimadaris Wikalat Alghawth Alduwaliat Bighazat , Bahath Muqadim Ealaa Almutamar Altarbuii Al'awal / Altarbiat fi Filastin Wataghayurat Aleasr Almuneaqad Bikuliat Altarbiat Fi Aljamieat Al'iislamiat 23 - 24 $/ 112004,($ D.N )

Eabd Allah, Mansur (2004): Wijhat Aldabt Ladaa Muelimi Watalamidh Almarhalat Alaibtidayiyat Waealaqatiha Bialtahsil Aldirasii Ladaa Huala' Altalamidh Dirasat Mueasirat fi Eilm Alnafs Altarbuii J 2./ Ealam Alkutub Alqahira .

Eads, Muhamad Eabd Alrahim (2002) Tadaniy Al'iinjaz Almadrasiu : 'Asbabih Waeilajuh, T2, Eamman : Dar Alfk. 